\title{
A CENTRAL DE MEDIDAS SOCIALMENTE ÚTEIS: ALTERNATIVAS PENAIS COM ENFOQUE RESTAURATIVO CONFORME A AGENDA 2030
}

THE CENTRAL OF SOCIALLY USEFUL MEASURES: CRIMINAL ALTERNATIVES WITH A RESTAURATIVE FOCUS ACCORDING TO THE 2030 AGENDA

\author{
José Laurindo de Souza Netto ${ }^{1}$ \\ Horácio Monteschio ${ }^{2}$ \\ Celso Hiroshi Iocohama ${ }^{3}$
}

\section{RESUMO}

Este artigo objetiva demonstrar como os conceitos de responsabilização, restauração e reintegração da Justiça Restaurativa são capazes de solucionar um problema de ordem social ocasionado em função de o mero encarceramento não ter obtido os resultados necessários para recuperar infratores penais. Com uma metodologia baseada na pesquisa de literatura jurídica sobre o tema, e principalmente nas orientações do Conselho Nacional de Justiça, buscou-se investigar como o Brasil acatou recomendações das Nações Unidas sobre a aplicação das penas alternativas. A implementação da Política Nacional de Justiça Restaurativa e das Centrais de Medidas Socialmente Úteis são abordadas como respostas ao aumento da reincidência de crimes. Complementa o trabalho a análise acerca da preocupação das autoridades judiciárias com a aplicação de medidas socialmente úteis, de modo a conscientizar os transgressores da legislação sobre as dificuldades para o ressarcimento de prejuízos das vítimas - enfatizando a cultura da paz preconizada pela Agenda 2030 da ONU.

PALAVRAS-CHAVES: justiça restaurativa. política nacional de justiça restaurativa. alternativas ao cárcere. sistema de aplicação de medidas socialmente úteis. central de medidas socialmente úteis. cemsu.

\footnotetext{
ABSTRACT

This article demonstrates how the concepts of responsability, restauration and reintegration of the Restorative Justice are capable of solving a problem of social order due to the fact that the

${ }^{1}$ Pós-Doutorado na Università degli Studi di Roma La Sapienza. Mestre e Doutor em Direito pela Universidade Federal do Paraná. Professor no curso de Mestrado da Universidade Paranaense - Unipar. Desembargador do Tribunal de Justiça do Paraná.

${ }^{2}$ Doutor em Direito pela FADISP. Mestre em Direitos da Personalidade pela UNICESUMAR. Com Estágio de Pós-doutorado pelo UNICURITIBA. Pós-Doutor em Direitos Humanos pelo Ius Gentium Conimbrigae da Faculdade de Direito da Universidade de Coimbra-Portugal. Professor de Direito Administrativo e Processo Administrativo do UNICURITIBA.

${ }^{3}$ Doutor em Direito pela Pontifícia Universidade Católica de São Paulo Educação, em Educação pela Universidade de São Paulo. Especialista em Docência pela Universidade Paranaense. Professor de Direito Processual Civil UNIPAR
} 
imprisonment has not been able to obtain the necessary results in recovering criminal offenders. Methodologically based on juridical literature research about the matter, and specially on the orientations of the National Council of Justice, this investigation questioned how Brazil accepted recommendations from the United Nations about the application of alternative punishments. The implementation of the National Politics of Restorative Justice and of the Centrals of Socially Useful Measures is addressed as an answer to the increased recurrence of crimes. The analysis about the concern of the judicial authorities with the application of socially useful measures, in order to raise awareness of the transgressors about the difficulties to compensation of victims' losses, emphasizing the culture of peace advocated by UN 2030's agenda, complements this work.

KEYWORDS: restorative justice. national politics of restorative justice. alternatives to prison. socially useful measures system application. centrals of socially useful measures

\section{Introdução}

Após um longo período vivenciado pelos seres humanos, no qual o tratamento dispensado aos infratores de regras era permeado de brutalidade, a Idade Média (476 a 1453) e todo o obscurantismo social, perpetrado por um sistema penal orientado pelas doutrinas fundamentalistas religiosas da época, foram confrontados por pensadores iluministas que apresentaram novas soluções a um problema que ainda hoje aflige as sociedades: a criminalidade.

O que deveria ser feito com uma pessoa que roubasse porque passava fome - um dos mais simples delitos - e qual punição poderia ser aplicada para o criminoso não se tornar reincidente sempre foram as questões levantadas por pensadores do movimento filosófico que ficou conhecido por Humanismo, em razão de ter atribuído maior importância à dignidade humana. Assim, tomou força a racionalidade, corrente que exigia fundamentação sensata para resolver problemas, e não soluções baseadas em emoções, sentimentos pessoais ou instintos.

Já no Renascimento, quando se passou a considerar o ser humano em posição central em relação a todo o Universo, o uso da razão levou novos pensadores a procurar por soluções orientadas pela proporcionalidade que deveria ser aplicada aos castigos impostos aos que cometiam atos condenáveis, inclusive nos aspectos ético, moral e social. O Iluminismo buscou terminar com as perseguições causadas pela intolerância, comportamento desenvolvido pela ignorância e falta de vontade de reconhecer e respeitar diferenças.

Assim, Jean-Jacques Rousseau (1712-1778), especialmente em sua obra Discurso sobre a origem e os fundamentos da desigualdade entre os homens (1755) - na qual o autor faz uma investigação acerca do sentimentos de autopreservação e de compaixão pelos infortúnios 
alheios -, desenvolveu sua tese, sintetizada na pergunta: Como conhecer, pois, a origem da desigualdade entre os homens, a não ser começando por conhecer o próprio homem?

A Filosofia possibilitou a compreensão de que o ser humano tem a capacidade de gerar infelicidade em função de sua ganância, por causa do estado de guerra que pode criar quando um homem se sobrepõe a outro, em uma tentativa de dominação, conforme nos explica Rousseau. E foi na tentativa de evitar o caos que surgiu a necessidade de leis serem estabelecidas para proteger direitos coletivos e individuais, protegendo-os ainda contra possíveis arbitrariedades cometidas pelos mais poderosos.

Os comportamentos inadequados recebiam castigos. Segundo Luis Francisco Carvalho Filho (2002), as atitudes condenáveis eram severamente combatidas: o malfeitor pagava pelos crimes cometidos, com punições que iam desde a amputação de membros do corpo ou o suplício com ferro em brasa, até a condenação à pena capital na temível e mortífera roda, que espedaçava o condenado; tais penas, hoje consideradas desnecessariamente cruéis, proporcionavam espetáculos à população.

Foi por causa de uma execução na roda que o escritor francês Voltaire (1694-1778) produziu seu famoso Tratado sobre a tolerância (1763), uma crítica a respeito de um dos casos de erro judicial mais emblemáticos da humanidade, o julgamento do comerciante Jean Calas, acusado de homicídio e condenado à morte em 1762, mesmo sem ter ficado provada sua culpa de forma irrefutável. A inocência foi declarada postumamente pelo Tribunal de Paris, em 1765.

A conciliação, a harmonização de um delinquente com os demais membros de uma comunidade continuava a ser buscada por filósofos e outros estudiosos. Da mesma forma que, na contemporaneidade, diferentes autoridades se debruçam em estudos sobre as possíveis respostas ao desafio de reintegrar pessoas, os pensadores da Idade Moderna na França, Inglaterra, Holanda e Itália também investigavam como o Direito Penal poderia evitar a incidência de crimes.

O inglês Thomas More (1478-1535), autor de Utopia (1516), já descrevia problemas e apresentava soluções, mesmo que fictícias, em sua ilha fantasiosa na qual uma república imaginária não conseguia lidar direito com criminosos. Naquela época, o reino da Inglaterra havia recrudescido a legislação penal, impondo a pena de morte para os delitos de furto e vadiagem, fazendo com que a população presenciasse enforcamentos cotidianamente. Mas as penas mais severas a criminosos não implicaram na diminuição da criminalidade. Pelo contrário, ladrões passaram a assassinar suas vítimas para não serem por elas denunciados. Apesar de a intenção de More, de melhorar a sociedade, ter ficado registrada na crítica social impressa nas páginas de sua obra fantástica, a situação da humanidade não foi modificada. 
A crueldade do sistema penal permaneceu, e foi preciso um pensador propor uma inovação que trouxe luz aos encarregados de determinar a dosimetria de penas a transgressores: Cesare Beccaria (1738-1794), o jurista e economista italiano que escreveu Dos Delitos e das Penas (1764), obra revolucionária no sentido de apresentar concepção de proporcionalidade entre a transgressão e a aplicação de punição. Esse filósofo lecionou que o magistrado deveria somente ficar encarregado de definir qual das sentenças escritas se adequaria ao delito, orientação responsável pela alteração de ordenamentos jurídicos de várias nações.

Para Beccaria, aquele era o momento adequado de examinar e distinguir as diferentes espécies de delitos e a maneira de puni-los. Ao defender tratamento humanitário, ensinou que as sanções não deveriam exceder a sua finalidade de prevenção. Logo, pode-se colocá-lo como um dos precursores da Justiça Restaurativa.

Após um salto temporal e já em solo pátrio, no Brasil do século XXI o Poder Judiciário brasileiro passa a promover ações e programas de aplicação de sanções de cunho restaurativo a infratores com base na política pública implementada pelo Conselho Nacional de Justiça, com a Resolução n. 225, de 31 de maio de 2016, que indica que o tratamento dos conflitos deve assegurar o direito à solução por meios adequados à sua natureza e peculiaridade.

Portanto, este trabalho se propõe a verificar como a Política Nacional de Justiça Restaurativa está funcionando e, ainda, como as alternativas ao cárcere se ajustam à Agenda 2030, principalmente na promoção da cultura da paz. Serão analisadas também a implementação do sistema de aplicação de medidas socialmente úteis e as respostas que o Poder Judiciário brasileiro dá para a busca de justiça que contemple tanto a responsabilização quanto a restauração e a reintegração.

\section{A Política Nacional de Justiça Restaurativa (Resolução n. 225, de 31 de maio de 2016, do Conselho Nacional de Justiça)}

A busca pela verdadeira justiça não significa, exclusivamente, a punição do culpado pelo ato considerado crime, e isso tem uma razão objetiva muito simples: se o indivíduo que cometeu o ato hostil simplesmente for encarcerado, jogado em alguma masmorra que vise à expiação de sua culpa, dificilmente teremos alguma recuperação efetiva daquele ser humano, que carregará ainda mais ódio e revolta contra um mundo que jamais o acolheu.

Por isso, há real necessidade de a sociedade pensar novas formas de enfrentamento do crime. A proteção das vítimas não deve resumir-se à penalização do indivíduo que seja 
considerado culpado, até porque, em algum momento, o agressor pode ter sido vítima e as suas escolhas violentas podem não ter sido tão livres quanto parecem.

A crítica a esse modelo punitivista, cujas consequências são perceptíveis no constante aumento da criminalidade, na superlotação carcerária e em uma sociedade cada dia mais assustada e insegura com a violência em sua volta, foi determinante para a busca de novos modelos de controle e coesão social, dado este modo simplesmente retributivista penal da sociedade ocidental não ter conseguido solucionar problemas que, diuturnamente, não cessam de se agravar.

Em suma, há uma crise de legitimidade do Direito Penal, cuja tibieza de fundamentos teoréticos representam as indesejáveis consequências na sociedade moderna. Nesse sentido, Marcelo L. Pelizzoli (2014, p. 1-2) vaticina:

\begin{abstract}
Falando diretamente, no século XX a ideia e a prática de justiça foram sequestradas pelo sistema legal, "judiciário", compondo um locus institucional e político legitimado para dar contas da problemática dos conflitos humanos, apoiado nos marcos do Direito; tal olhar tornou-se então reducionista. Caberia à chamada Justiça, agora institucionalizada e carreada pelos poderes legisladores - altamente dependentes dos poderes políticos, das tradições/elites do poder econômico - eleger uma pretensa neutralidade ao mesmo tempo que uma pretensa sacralidade como cernes de sua legitimação.
\end{abstract}

Desta forma, com uma visão mais holística e menos reduzida à racionalidade punitiva, com vistas não apenas ao isolamento espaço-temporal do suposto criminoso, mas na busca das causas do comportamento violento, da proteção da vítima e empoderamento social, novas formas de justiça foram buscadas.

Agora, não basta apenas punir, mas sim reconhecer as causas da violência e, principalmente, encontrar uma solução pacífica para o conflito social, em que as partes envolvidas possam ter a sua própria voz e se conciliar, restaurar o tecido social corrompido pela violência na comunidade. Mais do que punir, restaurar; mais do que uma Justiça Retributiva, uma Justiça Restaurativa.

Na lição da professora Ila Barbosa Bittencourt, temos a conceituação de Justiça Restaurativa:

Segundo Marcos Rolime Mylenne Jaccoud, foi o psicólogo Albert Eglash quem cunhou a expressão "justiça restaurativa", em seu trabalho Beyond restitution: creative restitution (1977). Nele, o cerne era a proposta de reabilitar o ofensor através do estímulo de pedir perdão e se retratar diante da vítima. E nele se insculpiu o mais importante princípio do movimento restaurativo, qual seja, a transformação do ser humano, dando a ele a chance para refletir sobre os seus erros e buscar caminhos a serem trilhados para repará-los de alguma maneira. 
Nesse sentido, a busca da consciência individual, da percepção do outro e da relação entre a vítima e o suposto agressor tornou-se o paradigma de superação de uma Justiça velha e desgastada, que não conseguia mais corresponder aos anseios naturais de paz e segurança da sociedade.

A origem desse novo paradigma, paradoxalmente, não veio da pós-modernidade, mas sim da percepção sobre o modo de vida de povos que, apesar de considerados "primitivos", possuíam relações sociais que não abarcavam a violência e a consequente desagregação encontradas nas sociedades ditas "modernas". Por óbvio, os instrumentos modernos de atuação estatal e jurisdicional tiveram que buscar ecos legislativos para abarcar essa nova concepção de justiça, centrada na defesa da vítima e na transformação do comportamento desviante, promovendo também a restauração da sociedade.

Buscando-se pela legislação brasileira, especialmente pela atuação do Conselho Nacional de Justiça, que possui muito mais agilidade técnica do que as composições das casas legislativas nacionais, percebe-se que a Resolução n. 125, de 29 de novembro de 2010, já esboça os primeiros passos para a abertura jurisdicional na busca de novos modos de tratamento adequado dos conflitos de interesse. Em seu art. $1^{\text {o }}$ já destaca que Fica instituída a Política Judiciária Nacional de tratamento dos conflitos de interesses, tendente a assegurar a todos o direito à solução dos conflitos por meios adequados à sua natureza e peculiaridade.

Essa nova Política Judiciária nacional possui o objetivo de promover ações de incentivo à autocomposição de litígios e à pacificação social por meio da conciliação e da mediação $\left(\operatorname{art.~} 4^{\circ}\right)$. Evidentemente, não basta apenas realizar o enfrentamento direto das partes envolvidas, com mera decisão judicial que estabelecesse lei entre essas partes, mas deve-se também buscar melhores instrumentos de apaziguamento social, especificamente em casos de conflitos de natureza civil.

Dessa forma, o foco na formação dos conciliadores, mediadores e facilitadores de círculos de Justiça Restaurativa tornou-se elemento de preocupação e de implementação de política pública, para que agentes especializados tenham a capacidade de trazer a possibilidade conciliatória, mediada pela atuação de profissionais da verdadeira pacificação social, praticantes de uma instauração de medidas restaurativas que não vise à mera imposição da norma legal, mas busque um encontro das vontades dos indivíduos, das partes, dos elementos nucleares de uma sociedade que tanto possa ser mais justa quanto viver em paz.

Com o sucesso desse novo paradigma conciliatório, o Conselho Nacional de Justiça elaborou a Resolução $\mathrm{n}^{\circ} 225$, de 31 de maio de 2016, que busca a institucionalização de mais uma evolução no tratamento da atuação jurisdicional, agora mais voltada a conflitos da seara 
penal, procurando menos punição e muito mais a restauração de uma sociedade maculada pela sua própria desagregação.

Mas a Resolução CNJ n. 225 não busca reinventar a roda. Sua inspiração é proveniente das recomendações da ONU para implantação da Justiça Restaurativa, especialmente a Resolução n. 2002/12, de 24 de julho de 2002, que instaura os Princípios Básicos Para Utilização de Programas de Justiça Restaurativa em Matéria Criminal, frutos do amadurecimento da Resolução n. 1999/26, de 28 de julho de 1999, intitulada Desenvolvimento e Implementação de Medidas de Mediação e Justiça Restaurativa na Justiça Criminal e também da Resolução n. 2000/14, de 27 de julho de 2000, intitulada Princípios Básicos para utilização de Programas Restaurativos em Matérias Criminais.

Assim, a resolução do CNJ em análise estabelece um conjunto ordenado e sistêmico de princípios, métodos, técnicas e atividades próprias, que visa à conscientização sobre os fatores relacionais, institucionais e sociais motivadores de conflitos e violência $\left(\right.$ art. $\left.1^{\circ}\right)$, que tem como princípios a corresponsabilidade, a reparação dos danos, o atendimento às necessidades de todos os envolvidos, a informalidade, a voluntariedade, a imparcialidade, a participação, o empoderamento, a consensualidade, a confidencialidade, a celeridade e a urbanidade (art. $2^{\circ}$ ).

É importante destacar que esses instrumentos jurídicos são produtos de construções doutrinárias que perceberam a ineficácia do sistema penal retributivo, trazendo, inclusive, uma redefinição do conceito de crime, conforme nos acrescenta Mylénne Jaccoud, citada por Ila Barbosa Bittencourt (2017), ao afirmar que:

\footnotetext{
O crime não é mais concebido como uma violação contra o Estado ou como uma transgressão a uma norma jurídica, mas como um evento causador de prejuízos e consequências. Uma tendência relativamente recente no decorrer da Justiça Restaurativa propõe reconstruir a noção de crime, especificando que o crime é mais que uma transgressão para uma norma jurídica.
}

Por isso, a restauração não ocorre por meio de punição. A transformação da sociedade e do indivíduo só pode ser efetivamente alcançada pela pacificação social plena e duradoura, em que a vítima seja ouvida e o agressor compreendido.

Reeducar e reinserir o agressor na sociedade, empoderar a vítima e, principalmente, proteger os direitos humanos constituem a finalidade da Justiça Restaurativa, de modo que seja superado o encarceramento, o punitivismo, a mera culpa e castigo, trazendo uma nova relação do homem com a sociedade, do indivíduo consigo mesmo.

Esta busca por alternativas a um paradigma já superado leva ao envolvimento na nova práxis da proximidade comunitária restaurativa, nas palavras de Marcelo L. Pelizzoli, Sandro 
C. Sayão e Maria de Fátima G. da Silveira (2012, p. 69), com uma dinâmica circular, num espaço de empoderamento mútuo que busque a segurança acima do medo, a consciência acima da pena e, enfim, o equilíbrio da sociedade acima do mero poder estatal opressor e vingativo.

Muito mais do que um novo modelo ou uma nova proposta simplista, a Justiça Restaurativa busca o encontro do homem consigo mesmo, com a sua própria consciência, destacando a responsabilidade da sociedade perante cada indivíduo e o empoderamento da vítima, que, em verdade, é a própria sociedade como um todo. Passa-se, portanto, a averiguar os principais conceitos da Justiça Restaurativa.

\subsection{Os pilares do paradigma restaurativo: responsabilização, interesse da vítima e reconstrução do tecido social}

A Resolução CNJ n. 225/2016 é marco legal importante na implementação da Justiça Restaurativa no país, gerando considerável incentivo para a execução dos procedimentos pautados nos métodos autocompositivos.

O documento define o que é Justiça Restaurativa e ressalta a importância da conscientização dos fatores sociais, institucionais, familiares e pessoais que porventura tenham motivado a violência, para promover a resolução adequada do conflito por meio de procedimentos autocompositivos que priorizem o diálogo entre as partes.

Segundo a referida norma, os programas restaurativos devem buscar a responsabilização daqueles que de alguma forma contribuíram para a ocorrência do fato danoso, promovendo a reparação do dano provocado e a recomposição da relação social rompida pelo conflito.

Importa enfatizar o $\S 2^{\circ}$ do sobredito ato normativo, que esclarece que o paradigma restaurativo não pretende excluir ou substituir por completo o procedimento da Justiça tradicional. Pelo contrário, deve ocorrer de forma concorrente ou alternativa, analisando-se caso a caso com o objetivo de atingir a melhor solução para as partes envolvidas e a comunidade.

Ademais, resta ressaltar a grande importância atribuída à vítima nos procedimentos restaurativos, permitindo sua atuação direta na solução do conflito através do diálogo construtivo com o ofensor e demais envolvidos no fato danoso. Os terceiros envolvidos podem ser representantes da comunidade, familiares e quaisquer outras pessoas que, direta ou indiretamente, tenham envolvimento com a situação.

A resolução também elenca os princípios que orientam a Justiça Restaurativa, a saber: reparação dos danos; informalidade; corresponsabilidade; atendimento às necessidades dos envolvidos; participação; imparcialidade; voluntariedade; confidencialidade; empoderamento; 
consensualidade; celeridade e urbanidade. É importante considerar que não se buscou esgotar os princípios da Justiça Restaurativa, mas sim ressaltar alguns cuja relevância para o procedimento restaurativo permeia toda a prática dos métodos autocompositivos.

Quanto ao procedimento, a Resolução explica o método restaurativo para aplicação no âmbito judicial, destacando a possibilidade de ser encaminhado pelo juiz, de ofício ou a requerimento das partes, pelos advogados das partes, pela Defensoria Pública, pelo Ministério Público ou pelos setores de Psicologia e Serviço Social, em qualquer fase do processo judicial. Além disso, prevê a possibilidade de a autoridade policial sugerir o encaminhamento das partes ao procedimento restaurativo antes mesmo da fase processual, em seu relatório do inquérito policial ou do termo circunstanciado.

$\mathrm{O} \mathrm{CNJ}$ orienta que os procedimentos restaurativos deverão ser realizados por um ou mais facilitadores, atuando como coordenadores no processo de escuta dos envolvidos, em quantas sessões se fizerem necessárias, propiciando o diálogo e a construção da melhor solução do caso concreto. Se houver acordo, o Ministério Público será ouvido e o juiz homologará.

Ressalte-se que a Justiça Restaurativa consiste em uma medida mais humanizada da persecução penal, pautada na conscientização sobre os fatores sociais e institucionais motivadores do conflito e da violência, buscando-se, por meio de técnicas autocompositivas, a reparação dos traumas causados pelo crime. Em outras palavras, esse modelo consiste $n a$ aproximação dos indivíduos ligados a um conflito [...], unidos com o objetivo de minimizar as consequências negativas decorrentes de determinada infração, [de modo a] resolver o próprio litígio ou reconciliar as partes (PINHEIRO, 2013, p. 117-128).

Assim, o paradigma restaurativo busca entender as razões que levaram o infrator a cometer o fato danoso e por meio desses dados facilitar a autoresponsabilização e a reinclusão social, restaurando sua relação com a sociedade. Segundo a lição de Renato Sócrates Gomes Pinto (2010, p. 13-31):

O crime, para a justiça restaurativa, não é apenas uma conduta típica e antijurídica que atenta contra bens e interesses penalmente tutelados, mas, antes disso, é uma violação nas relações entre o infrator, a vítima e a comunidade, cumprindo, por isso, à Justiça identificar as necessidades e obrigações oriundas dessa violação e do trauma causado e que deve ser restaurado, oportunizar e encorajar as pessoas envolvidas a dialogarem e a chegarem a um acordo, como sujeitos centrais do processo, sendo ela, a Justiça, avaliada segundo sua capacidade de fazer com que as responsabilidades pelo cometimento do delito sejam assumidas, as necessidades oriundas da ofensa sejam satisfatoriamente atendidas e a cura, ou seja, um resultado individual e socialmente terapêutico seja alcançado. 
Nesse contexto, a Justiça Restaurativa amplia a abordagem e tenta entender o conflito gerado pelo evento danoso como algo maior e mais complexo, afastando o foco absoluto de enquadramento de uma conduta a um determinado tipo penal para relevar o dano causado e as formas de sua reparação.

Buscando atingir a solução mais adequada para o conflito, a Justiça Restaurativa utiliza técnicas de responsabilização daqueles que direta ou indiretamente contribuíram para o fato danoso. Ao invés de receber punição de encarceramento pelo ato, nas práticas restaurativas o ofensor é responsabilizado pelas consequências da infração, ficando obrigado a reparar os prejuízos causados a vítima. Essa é uma forma racional de reincluir o infrator no meio social.

Ressalte-se que a Justiça Restaurativa atribui grande importância à vítima durante todo o procedimento, preocupando-se em oferecer apoio e assistência ao que sofre diretamente as consequências da infração, da irresponsabilidade ou da violência. $\mathrm{O}$ paradigma restaurativo demonstra a importância da vítima no processo de responsabilização do infrator, não tratando qualquer das partes como mera parte processual, mas como alguém que precisa de atenção e apoio.

O foco não é voltado para uma resposta punitiva, mas para a relação afetada com o evento danoso, afastando a ideia de que o conflito deve ser apagado, rechaçado, estabelecendo o que deve ser trabalhado e que pode ser positivo. Por isso, diz-se que a Justiça Restaurativa não se funda exclusivamente no ato delitivo (violação da lei - modelo retributivo) nem na pessoa do autor, mas no próprio evento do encontro entre as pessoas, proporcionando novas perspectivas e novos olhares sobre a situação que as envolve (ACHUTTI, 2016, p. 85). Os procedimentos restaurativos devem ser realizados por intermédio de um ou mais facilitadores, que viabilizarão o diálogo entre os envolvidos para encontrar a melhor solução do caso concreto.

No próximo item, será analisada a evolução da Resolução n. 288/2019, ocorrida com a edição da orientação do CNJ que determinou a política institucional do Poder Judiciário para a promoção da aplicação de alternativas penais, com enfoque restaurativo, em substituição à privação de liberdade.

\section{A política de alternativas penais com enfoque restaurativo (o paradigma restaurativo)}

\section{- Resolução n. 288, de 25 de junho de 2019, do Conselho Nacional de Justiça}


Com o objetivo de reduzir índices de encarceramento e de reincidência, o Conselho Nacional de Justiça editou a Resolução n. 225, em 2016, conforme destacado no item 2.1, que abordou a Política Nacional de Justiça Restaurativa.

Em poucos anos, vários centros de estudos se espalharam por todos os 27 Tribunais de Justiça e os cinco Tribunais Regionais Federais, aos quais também se juntaram tanto unidades do Ministério Público quanto da Defensoria Pública, que se empenharam para desenvolver práticas diferenciadas da conciliação e da mediação, já que são as partes que atuam de maneira coletiva na restauração do dano causado, com a intervenção de um facilitador.

Todavia, a assombrosa estatística de encarceramento não parou de aumentar. No final de agosto de 2019, o Conselho Nacional do Ministério Público (CNMP) divulgou o resultado da pesquisa Sistema Prisional em Números, revelando que o Brasil possui mais de 810 mil presidiários. Um pouco antes desta estatística ter sido revelada, porém, em 25 de junho de 2019, o CNJ editou a Resolução n. 288, com a finalidade de instituir no Poder Judiciário uma política de promoção da aplicação de alternativas penais, com enfoque restaurativo, em substituição à privação de liberdade, conforme o texto de seu primeiro artigo. No art. $2^{\circ}$ dessa resolução há a conceituação de alternativas penais como sendo as medidas de intervenção em conflitos e violências, diversas do encarceramento. Isso significa haver preocupação por parte do poder público com a problemática da superlotação dos presídios.

O ministro Gilmar Mendes, do Supremo Tribunal Federal, em entrevista aos jornalistas Aiuri Rebello, Eduardo Militão, Flávio Costa e Luís Adorno, publicada no caderno Cotidiano, do UOL, afirmou que o sistema carcerário está 'submetido a uma regra de caos', mas a ressocialização é uma solução possível.

A segunda parte do mencionado art. $2^{\circ}$ da Resolução CNJ n. 288/2019 especifica que as medidas do Poder Judiciário devem ser:

[...] orientadas para a restauração das relações e a promoção da cultura da paz, a partir da responsabilização com dignidade, autonomia e liberdade, decorrentes da aplicação de: I - penas restritivas de direitos; II - transação penal e suspensão condicional do processo; III - suspensão condicional da pena privativa de liberdade; IV - conciliação, mediação e técnicas de justiça restaurativa; V - medidas cautelares diversas da prisão; e VI - medidas protetivas de urgência (grifos nossos).

É importante destacar, ainda, que o Levantamento Nacional de Informações Penitenciárias (Infopen), banco de dados com informações penitenciárias elaborado pelo Departamento Penitenciário Nacional, torna claro que os registros de encarceramento englobam maiores de 18 anos em situação de privação de liberdade, assim entendida como a pessoa sobre 
a qual recaia medida cautelar ou pena de prisão, medida de segurança de internação ou prisão civil, e que esteja sob a efetiva custódia do Estado em estabelecimento penal. Ou seja, os adolescentes cumprindo medidas socioeducativas não estão relacionados no levantamento estarrecedor sobre o número de presos no Brasil.

Ressalte-se que os órgãos do sistema de Justiça brasileiro também aplicam as medidas diversas do encarceramento aos menores de idade infratores. De acordo com o art. $9^{\circ}$ da Resolução CNJ n. 288/2019, são atribuições do Fórum Nacional de Alternativas Penais (Fonape), vinculado ao Departamento de Monitoramento e Fiscalização do Sistema Carcerário e do Sistema de Execução de Medidas Socioeducativas (DMF), as seguintes tarefas:

I - propor diretrizes para a política pública do Poder Judiciário relacionada à política de alternativas penais, em complementação à presente Resolução;

II - propor medidas voltadas à promoção da aplicação de alternativas penais, com enfoque restaurativo, em substituição à privação de liberdade, contribuindo para a desconstrução da cultura do encarceramento em massa;

III - propor ao CNJ a realização de pesquisas que subsidiem a política de alternativas penais;

IV - promover a identificação e sistematização de boas práticas desenvolvidas para o campo das alternativas penais, com análises periódicas de dados, indicadores, metodologias, abrangência e resultados;

$\mathrm{V}$ - estabelecer, em conjunto com o DMF, regulamento interno para definir estruturas e fluxo regular de funcionamento.

Entre as alternativas penais relacionadas no art. $3^{\circ}$ da Resolução n. 288 destacam-se algumas com direta ligação aos propósitos da Justiça Restaurativa, mais especificamente as dispostas nos incisos I, V, VI, VII, VIII, IX e XI, a saber:

[...] a redução da taxa de encarceramento mediante o emprego restrito da privação de liberdade [...] a dignidade, a autonomia e a liberdade das partes envolvidas nos conflitos; a responsabilização da pessoa submetida à medida e a manutenção do seu vínculo com a comunidade; o fomento a mecanismos horizontalizados e autocompositivos, a partir de soluções participativas e ajustadas às realidades das partes; a restauração das relações sociais, a reparação dos danos e a promoção da cultura da paz [...]; a proteção social das pessoas em cumprimento de alternativas penais e sua inclusão em serviços e políticas públicas [...]; a articulação entre os órgãos responsáveis pela execução, aplicação e acompanhamento das alternativas penais.

As orientações para o bom funcionamento dos serviços de acompanhamento das alternativas penais dispostas no art. $6^{\circ}$ da Resolução em análise apresentam seis competências que as varas especializadas em execução de penas e medidas alternativas - cuja criação foi 
determinada pela Resolução n. 101 do CNJ, publicada em 25 de janeiro de 2009 - deverão contemplar:

\footnotetext{
I - execução das penas e medidas alternativas, de forma articulada com os serviços de acompanhamento instituídos pelo Poder Executivo ou, nas comarcas ou seções judiciárias em que os serviços ainda não estiverem instituídos, por meio de serviço psicossocial instituído junto à vara;

II - estabelecer rotinas e formas simplificadas de funcionamento e de comunicação de seus atos aos cumpridores das medidas;

III - articular com o Poder Executivo os procedimentos e fluxos adequados ao encaminhamento para cumprimento das penas e medidas alternativas;

IV - estimular a aplicação de alternativas penais, em substituição à privação de liberdade, nas varas com competência criminal;

V - participar dos espaços de formulação e discussão da política de alternativas penais; $\mathrm{e}$

VI - fomentar o controle e a participação social nos processos de formulação, implementação, execução, monitoramento e avaliação da política de alternativas penais.
}

Os operadores do Direito envolvidos nas ações relacionadas no art. $6^{\circ}$ da Resolução CNJ n. 288/2019 devem ter em mente que, de acordo com a aplicação recomendada de competências de Justiça Restaurativa, nas reuniões mediadas por um facilitador entre vítima e ofensor, deve ser sempre a vítima quem terá prioridade para decidir onde, quando e o tempo de duração do procedimento. É dessa maneira que as partes poderão resolver como será possível reparar os danos causados por aquele que tiver dado causa a qualquer espécie de prejuízo.

A promoção da cultura da paz, levando em consideração o princípio da dignidade da pessoa humana, constitui o fundamento da Justiça Restaurativa. Os projetos e ações atualmente desenvolvidos em todos os estados e no Distrito Federal estão em conformidade com a Agenda 2030, que contém as metas de desenvolvimento sustentável estabelecidas pelas Nações Unidas, cujo Objetivo 16 inclui justiça e paz social, conforme descrito no próximo item.

\section{Alternativas ao cárcere: Agenda 2030}

Um destaque importante para a melhor aplicação de medidas alternativas ao cárcere é que a estatística demonstrada no item anterior, de mais de 810 mil pessoas presas no Brasil, também revela um percentual de mais de $40 \%$ desse total não ter condenação. De acordo com informações do Banco de Monitoramento de Prisões, do Conselho Nacional de Justiça (CNJ), mais de 337 mil são presos provisórios.

Várias medidas de Justiça Restaurativa capazes de evitar que pessoas sejam encarceradas já foram propostas pelo Conselho Econômico e Social da ONU (ECOSOC), organismo das Nações Unidas responsável por formular recomendações sobre direitos 
humanos, dentre outras atribuições. Em 2018, o Brasil foi eleito para integrar esse conselho, que agrupa 54 Estados-membros eleitos pela Assembleia Geral.

Nos Objetivos de Desenvolvimento Sustentável (ODS) das Nações Unidas, também conhecidos como Agenda 2030, foi estabelecido um plano de ação com metas bem-definidas que deverão ser cumpridas até 2030. Entre os vários temas, o Objetivo n. 16 ressalta que os países-membros devem garantir que as pessoas alcancem a paz: Promover sociedades pacíficas e inclusivas para o desenvolvimento sustentável, proporcionar o acesso à justiça para todos é um compromisso firmado pelas 193 nações, incluindo o Brasil, que está obrigado a tomar medidas transformadoras.

Mais recentemente, em fevereiro de 2017, o ex-representante para a América do Sul do Alto Comissariado das Nações Unidas para os Direitos Humanos (ACNUDH), Amerigo Incalcaterra, visitou o Brasil. Nas reuniões que teve com autoridades brasileiras, em especial o ex-procurador-geral da República, Rodrigo Janot, e a então presidente do Supremo Tribunal Federal (STF) e do Conselho Nacional de Justiça, ministra Carmen Lúcia, os assuntos abordados envolveram, entre outros, a crise penitenciária e as alternativas penais, inclusive versando sobre a ultrapassada visão que clama por mais encarceramento e a consequente construção de mais cadeias: segundo Incalterra, medidas focadas só no encarceramento e na construção de novas prisões não são adequadas para enfrentar a situação. As alternativas penais e a ressocialização também devem ser incluídas no debate.

São vários os Juizados de Violência Doméstica e Familiar Contra a Mulher espalhados por todo o país, nos quais os resultados das reuniões de Justiça Restaurativa têm promovido paz social e recuperado homens com um passado de cultura machista, que usavam de violência contra suas companheiras como forma de controle. Depois de terem sido restaurados, eles passaram a enxergar novos horizontes, modificando seus comportamentos, a ponto de posteriormente proferirem palestras para outros homens em situações análogas àquelas nas quais se encontravam antes de terem participado das seções mediadas. Dessa maneira, o Judiciário não precisou levá-los ao encarceramento com base na Lei Maria da Penha (Lei n. 11.340/2006).

No Tribunal de Justiça do Paraná, por exemplo, a Segunda Vice-Presidência (biênio 2019/2020), visando dar atendimento à Agenda 2030, inciou vários projetos adequados às metas estipuladas pela ONU ao firmar convênios com prefeituras e o governo do estado, universidades, Defensoria Pública e Ministério Público, além das Polícias Militar e Civil e Guarda Municipal, de modo, a cumprir, em especial, o Objetivo 16. 
O Mapeamento dos Programas de Justiça Restaurativa (2019, p. 14), pesquisa realizada durante os meses de fevereiro a abril de 2019, revela que, entre os temas de maior interesse para capacitação e implantação das práticas restaurativas - considerando as unidades do Judiciário que possuem e os que não possuem iniciativas de Justiça Restaurativa (2019, p. 38) -, os programas que atendem a questões de tráfico e porte de drogas respondem por 31,9\% das ações. Entretanto, ainda temos um percentual bastante elevado de presos provisórios acusados de portar drogas. As ações de Justiça Restaurativa brasileiras, portanto, ainda terão de caminhar bastante no sentido de evitar excessos estatais sobre as pessoas que fazem uso recreativo de drogas, atentando para suas obrigações de direitos humanos e também aos Objetivos de Desenvolvimento Sustentável.

Vale destacar que a implementação de paz, estabilidade, direitos humanos e governança efetiva, baseada no estado de direito e pensada pelos países-membros das Nações Unidas e que levaram ao estabelecimento do Objetivo 16 da Agenda 2030, foram os aspectos considerados na idealização do projeto "Sistema de Aplicação de Medidas Socialmente Úteis como Substitutivo Penal", discutido no próximo item.

\section{O sistema de Aplicação de Medidas Socialmente Úteis e a CEMSU como central de recuperação de infratores}

Após ter percorrido toda a sistemática da implementação da Política Política Nacional de Justiça Restaurativa, estabelecida pela Resolução n. 225, de 31 de maio de 2016, do Conselho Nacional de Justiça, a Segunda Vice-Presidência do Tribunal de Justiça do Paraná no biênio 2019/2020 implementou uma mudança nos paradigmas de encarceramento, uma medida que resultou na cultura de paz pretendida pela Organização das Naçoes Unidas quando propôs a Agenda 2030.

A iniciativa procurou alinhar os projetos de Justiça Restaurativa ao Objetivo 16 da Agenda 2030 da ONU, de modo a promover sociedades pacíficas e inclusivas para o desenvolvimento sustentável, proporcionar o acesso à justiça para todos e construir instituições eficazes, responsáveis, conforme pode ser notado no projeto intitulado Sistema de Aplicação de Medidas Socialmente Úteis como Substitutivo Penal, que também foi elaborado de acordo com a Resolução n. 288, de 2019.

Esse projeto do Tribunal de Justiça do Paraná chegou em boa hora, já que a pesquisa Estudo da Imagem do Poder Judiciário, de setembro de 2019, elaborada pela Associação dos Magistrados Brasileiros (AMB) em parceria com a Fundação Getulio Vargas (FGV) revelou 
que, apesar de haver alto grau de confiança dos cidadãos no Poder Judiciário, superando o Executivo e o Legislativo, os entrevistados disseram ser motivo de desmotivação o fato de a Justiça ser "muito lenta e burocrática".

Os pilares da justiça restaurativa, isto é, responsabilização, interesse da vítima e reconstrução do tecido social, são os objetivos da implementação das Centrais de Medidas Socialmente Úteis (CEMSU) em vários municípios paranaenses, uma experiência inovadora e ao mesmo tempo reintegradora, pois são vários os casos de infratores penais que acabam se recuperando em uma das reuniões mediadas nas quais a alternativa ao cárcere produz resultado verdadeiramente restaurador.

Destaque-se que a aplicação de medidas socialmente úteis com enfoque restaurativo, em substituição à mera aplicação de prestação pecuniária e multa e de privação de liberdade, o objetivo principal do mencionado projeto do TJ/PR, já em funcionamento em diversas varas de Justiça, oferece um tipo de tratamento humanizado, no qual o ofensor ou criminoso é respeitado e tem a oportunidade de falar sobre os problemas que o levaram a delinquir, propiciando efeito educativo, prevenindo a reincidência.

É importante destacar que o TJ/PR também firmou convênios para levar cursos e orientações às faculdades de Direito, Serviço Social e Psicologia, oferecendo aos futuros profissionais dessas áreas do conhecimento a visão de que, na maioria dos casos, o encarceramento é um incremento à criminalidade. É possível observar a ineficácia desse sistema, que não intimida, não reabilita, pelo contrário, causa dor e sofrimento, segundo a apresentação do projeto analisado.

Como leciona Damásio de Jesus (2000), o modelo ressocializador tem demonstrado capacidade reabilitadora, reforçando a tese de que a prisão não deve ser um instrumento de vingança, mas sim de reinserção do indivíduo na sociedade.

O levantamento do CNJ intitulado Mapeamento dos Programas de Justiça Retaurativa (2019), aponta que todos os Tribunais de Justiça e ainda vários outros órgãos do Poder Judiciário e do Ministério Público implantaram projetos para transformar a sociedade por meio da reabilitação do indivíduo que tenha cometido um delito, uns em etapa mais avançada de desenvolvimento do que outros, mas todos defendendo a concepção de que a ressocialização levada a cabo através do atendimento em uma das Centrais de Medidas Socialmente Úteis é perfeitamente eficaz para o resultado pretendido de reinserir o ofensor na sociedade, educandoo para ter responsabilidade e, assim, não voltar a cometer delitos, ofensas ou causar prejuízos a outrem. 
Importa destacar as finalidades de coexistência pacífica do aludido projeto que criou o Sistema de Aplicação de Medidas Socialmente Úteis, em que a capacidade de resolução de conflitos do ser humano obtém relevância para, de maneira autônoma e pacífica, ser alcançado o que foi determinado pelas Nações Unidas no Objetivo 16 da Agenda 2030. Segundo a exposição de motivos deste projeto, o sistema consensual para a aplicação das medidas socialmente úteis tem seu foco na solução do problema de fundo que deu causa ao cometimento da infração penal. Tal circunstância cria situações jurídicas multifacetárias que envolvem matérias pertencentes à jurisdição extrapenal (familiar, civil, trabalhista, dentre outras), numa adequação em sintonia com a promoção da cultura da paz.

As medidas de responsabilização dos autores de infrações penais tanto propiciam a reintegração social como também a redução das taxas de reincidência, em razão de possibilitar a efetiva participação do ofendido no processo de aplicação de alternativas ao cárcere, resultando em menores custos de combate à criminalidade para o Estado.

\section{Conclusão}

Pelo exposto, verificou-se que a humanidade tem tentado solucionar diferentes problemas que surgiram com a convivência dos seres humanos e a construção de comunidades. A criminalidade parece ter sempre acompanhado as sociedades, que não souberam encontar medidas para efetivamente estancar delitos, especialmente em razão de a mera aplicação de penas não solucionar nem prevenir a incidência de infrações penais.

A Política Nacional de Justiça Restaurativa proposta pelo Conselho Nacional de Justiça, cujos pilares de responsabilização, interesse da vítima e reconstrução do tecido social se destacam, estimulou diferentes órgãos públicos para implementarem medidas de alternativas penais com enfoque restaurativo, desde a Defensoria Pública, Justiças Federal e Estadual, Ministério Público e outras entidades não-governamentais.

Parcerias foram firmadas com o objetivo de aplicar procedimentos restaurativos mediados por um ou mais facilitadores, de modo que os envolvidos, vítima, ofensor e outros, participem de sessões nas quais o diálogo possa propiciar a melhor solução do caso, sempre com a responsabilização e a busca da restauração.

Alternativas ao cárcere em conformidade com a Agenda 2030 da ONU são cada vez mais implementadas no âmbito do Poder Judiciário brasileiro, procurando promover a pacificação social plena e duradoura, assim como reduzir índices de encarceramento e de reincidência. 
Por fim, vê-se que a instauração do sistema de aplicação de medidas socialmente úteis e as Centrais de Medidas Socialmente Úteis têm demonstrado eficácia na recuperação de infratores e se estendido a várias comarcas espalhadas pelo país.

Embora em algumas áreas a Justiça Restaurativa ainda não tenha surtido efeito, a restauração por meio de sessões em que ofensores e infratores percebam a necessidade de apresentarem comportamento comprometido com a cidadania tem se demonstrado eficaz na prevenção e também na redução de reincidência.

Espera-se que os exemplos amplamente divulgados na imprensa e nas redes de comunicação do Judiciário, da Defensoria e do Ministério Público sirvam de alento para que a sociedade, em parceria com órgãos públicos, avance nas ações promotoras da cultura da paz.

\section{Referências}

ACHUTTI, Daniel Silva. Justiça restaurativa e abolicionismo penal: contribuições para um novo modelo de administração de conflitos no Brasil. 2. ed. rev. e atual. São Paulo: Saraiva, 2016.

ASSOCIAÇÃO DOS MAGISTRADOS BRASILEIROS. FGV. Estudo da imagem do Judiciário brasileiro. Recife: Ipespe, 2019.

BECCARIA, Cesare Bonesana, Marquese Di, 1738-1793. Dos delitos e das penas. Trad. J. Cretella JR. e Agnes Cretella. 2. ed. rev., São Paulo: Revista dos Tribunais. 1999.

BELIEIRO JÚNIOR, José Carlos Martines. Política e desenvolvimento no Brasil contemporâneo: a experiência do setor automotivo nos anos 90.. Relações Internacionais no Mundo Atual, [S.1.], v. 2, n. 14, p. 17 - 29, ago. 2012. ISSN 2316-2880. Disponível em: $<$ http://revista.unicuritiba.edu.br/index.php/RIMA/article/view/358/287>. Acesso em: 24 abr. 2020. doi:http://dx.doi.org/10.21902/Revrima.v1i15.358.

BITTENCOURT, Ila Barbosa. Justiça restaurativa. In: CAMPILONGO, Fernandes Celso; GONZAGA, Alvaro de Azevedo; FREIRE, André Luiz (Coord.). Enciclopédia Jurídica da PUCSP: teoria geral e filosofia do direito. São Paulo: Pontifícia Universidade Católica de São Paulo, 2017. Disponível em: https://enciclopediajuridica.pucsp.br/verbete/138/edicao1/justica-restaurativa. Acesso em: 3 dez. 2019.

BRASIL, Deilton Ribeiro. A JUSTIÇA RESTAURATIVA COMO ALTERNATIVA NO TRATAMENTO DE CONFLITOS NA ADMINISTRAÇÃO DA JUSTIÇA PENAL. Revista Juridica, [S.1.], v. 3, n. 40, p. 322 - 340, jan. 2016. ISSN 2316-753X. Disponível em: $<$ http://revista.unicuritiba.edu.br/index.php/RevJur/article/view/1363/920>. Acesso em: 24 abr. 2020. doi:http://dx.doi.org/10.21902/revistajur.2316-753X.v3i40.1363. 
CARVALHO FILHO, Luis Francisco. Prisão. Publifolha. São Paulo, 2002.

CONSELHO NACIONAL DE JUSTIÇA. Resolução $n$. 125, de 29/11/2010. Dispõe sobre a Política Judiciária Nacional de tratamento adequado dos conflitos de interesses no âmbito do Poder Judiciário e dá outras providências. Disponível em: https://www.cnj.jus.br/busca-atosadm?documento=2579. Acesso em: 3. dez. 2019.

CONSELHO NACIONAL DE JUSTIÇA. Resolução $n$. 225, de 31/05/2016. Dispõe sobre a Política Nacional de Justiça Restaurativa no âmbito do Poder Judiciário e dá outras providências. Disponível em: http://cnj.jus.br/busca-atos-adm?documento=3127. Acesso em: 3. dez. 2019.

CONSELHO NACIONAL DE JUSTIÇA. Mapeamento dos programas de Justiça restaurativa. Brasília: CNJ, 2019.

JESUS, Damásio Evangelista de. Penas Alternativas. São Paulo: Saraiva, 2000.

MORE, Thomas. Utopia. Trad. Anah de Melo Franco. Brasília: Editora Universidade de Brasília: Instituto de Pesquisa de Relações Internacionais, 2004.

NASCIMENTO, Josefa Florencio do; PESSINA, Fabio Nascimento. PENAL: NORMA BRASILEIRA E O INSTITUTO DA JUSTIÇA RESTAURATIVA NO COMBATE A CORRUPÇÃO ECONÔMICA NO PAÍS. Percurso, [S.1.], v. 4, n. 27, p. 267 - 284, dez. 2018. ISSN 2316-7521. Disponível em: <http://revista.unicuritiba.edu.br/index.php/percurso/article/view/3175/371371707>. Acesso em: 24 abr. 2020.

ONU. Resolução n. 2002/12-ONU. Instaura os Princípios Básicos Para Utilização De Programas De Justiça Restaurativa Em Matéria Criminal. Disponível em: http://www.juridica.mppr.mp.br/arquivos/File/MPRestaurativoEACulturadePaz/Material_de_ Apoio/Resolucao_ONU_2002.pdf. Acesso em: 3. dez. 2019.

ONU. Agenda 2030. Plano de Ação Para As Pessoas, Para o Planeta e Para a Prosperidade. Disponível em: https://nacoesunidas.org/pos2015/agenda2030. Acesso em: 3. dez. 2019.

ONU. ONU: penas alternativas e ressocialização devem fazer parte do debate sobre sistema penitenciário. 14 fev. 2017. Disponível em: https://nacoesunidas.org/onu-penas-alternativas-eressocializacao-devem-fazer-parte-do-debate-sobre-sistema-penitenciario/. Acesso em: 4 dez. 2019.

ONU. ONU pede alternativas à prisão para quem sofre com dependência das drogas. 26 jun. 2019. Disponível em: https://nacoesunidas.org/onu-pede-alternativas-a-prisao-para-quemsofre-com-dependencia-das-drogas/. Acesso em: 5 dez. 2019. 
PELIZZOLI, Marcelo L.; SAYÃO, Sandro C.; SILVEIRA, Maria de Fátima G. da. Humanização: Notas sobre Justiça Restaurativa. In: Universidade e sociedade em diálogo: temos fome de quê? SANTOS, Wellington Pinheiro dos; MELO, Jowania Rosas de; NUNES, Maria Christina de Medeiros; SOUZA, Edilson Fernandes de. (Org.). Recife: PROEXT, 2012.

PINHEIRO, Karina Bezerra; CHAVES, Raul Rocha. Justiça restaurativa: uma análise sociológica dos fins que os meios punitivos não alcançam. FIDES: Revista de Filosofia do Direito, do Estado e da Sociedade, Rio Grande do Norte, v. 4, n. 1, p.117-128, jan./jun. 2013 [revista eletrônica].

PINTO, Renato Sócrates Gomes. A construção da justiça restaurativa no Brasil. In: Revista Paradigma, Ribeirão Preto, v. 15, n. 19, p. 13-31, jan./jul. 2010.

REBELLO, Aiuri; MILITÃO, Eduardo; COSTA, Flávio; ADORNO, Luís. Prender demais é fornecer mão de obra barata para PCC, diz Gilmar Mendes. Brasília: UOL/Cotidiano, 4 dez. 2019. Disponível em: https://noticias.uol.com.br/cotidiano/ultimasnoticias/2019/12/04/prender-demais-encarceramento-fornecer-mao-de-obra-pcc-gilmarmendes-stf.htm?. Acesso em: 4 dez. 2019.

ROLIM, Marcos. Justiça Restaurativa: para além da punição. Disponível em: <http://www.susepe.rs.gov.br/upload/1327493829_Para\%20Alem\%20da\%20Pris\%C3\%A3o. pdf> Acesso em: 03 dez. 2019.

ROUSSEAU, Jean-Jacques. Discurso sobre as origens e fundamentos da desigualdade entre os homens. Trad. Maria Ermantina Galvão. 2. ed., São Paulo: Martins Fontes, 1999.

TRIBUNAL DE JUSTIÇA DO PARANÁ. TJPR inaugura novos serviços de atendimento ao cidadão em CEJUSCs do interior. Notícias. TJ/PR. 14 set. 2019 Disponível em: https://www.tjpr.jus.br/noticias/-/asset_publisher/9jZB/content/tjpr-inaugura-novos-servicosde-atendimento-ao-cidadao-em-cejuscs-do-interi-1/18319. Acesso em: 6 dez. 2019.

VOLTAIRE. Tratado sobre a tolerância. São Paulo, Folha de São Paulo, 2015. 